\title{
A Validation Procedure for Landscape Connectivity Approaches: Evaluation of The Accuracy of Ecological Corridor Locations.
}

Etienne Lalechère ( $\sim$ lalechereetienne@gmail.com )

INRAE: Institut National de Recherche pour l'Agriculture I'Alimentation et l'Environnement https://orcid.org/0000-0002-8920-731X

\section{Laurent Bergès}

INRAE: Institut National de Recherche pour l'Agriculture I'Alimentation et l'Environnement

\section{Research Article}

Keywords: Landscape permeability, Landscape fragmentation, Cost, friction or resistance surfaces, Habitat suitability modelling, Maxent models, Circuitscape

Posted Date: April 26th, 2021

DOI: https://doi.org/10.21203/rs.3.rs-435087/v1

License: (a) (i) This work is licensed under a Creative Commons Attribution 4.0 International License. Read Full License 


\section{Abstract}

\section{Context}

Connectivity conservation analysis is based on a wide range of approaches designed to locate key ecological corridors in order to maintain multispecies flows. However, the lack of validation procedures with accessible data prevents from selecting the most accurate approach.

\section{Objectives}

We propose a new validation procedure to evaluate the accuracy of ecological corridor locations in landscape connectivity approaches. We applied this procedure to compare three modelling approaches and select the most accurate.

\section{Methods}

Our procedure validates ecological corridor tracks with independent presence-only data, under the hypothesis that species should be present within or near the corridors (according to resistance distance) if the corridors have been correctly modelled. We applied Maxent and circuit theory to locate ecological corridors for forest bird species in a rural landscape following three approaches based on land cover, umbrella species and multispecies presence data. We compared the proportion of overlaid corridors among the three approaches, and selected the most accurate one according to our validation index.

\section{Results}

The corridors modelled from species presence data (umbrella and multispecies approaches) were more consistent than the habitat-based (land cover) approach. The multispecies approach was the most accurate while habitat approach was the least accurate in locating ecological corridors.

\section{Conclusions}

Our procedure can be used to: (1) evaluate the accuracy of the location of ecological corridors, (2) select the best approach to locate ecological corridors, and (3) validate the underlying assumptions of landscape connectivity approaches (e.g. dispersal and matrix resistance values).

\section{Introduction}

The increase in anthropogenic pressures has greatly affected species movement worldwide (Tucker et al. 2018). The dispersal of individuals among populations is essential to counterbalance the negative effects of habitat isolation and to maintain population and community persistence and dynamics (Hanski 1998; Vellend 2010). Ecological corridors that ensure dispersal can be defined as linear strips that provide a near continuous pathway promoting functional connectivity between core areas of biodiversity (Taylor et al. 1993; Gilbert-Norton et al. 2010; Resasco 2019). The concept of ecological 
corridors was integrated into landscape management strategies to maintain or restore ecological functions for species with multiple requirements (e.g. Pan European Ecological Network, Jongman et al. 2011). Key conceptual frameworks and accessible tools based on graph and circuit theory have been proposed to help locate ecological corridors through landscape connectivity analysis (McRae et al. 2008; Foltête et al. 2012; Saura and Torné 2009). However, these frameworks are based on different, and often untested, assumptions (e.g. dispersal or matrix resistance) that can lead to inconsistent spatial prioritization (Avon and Bergès 2016; Keeley et al. 2016; Meurant et al. 2018). To overcome this issue, empirical procedures are needed to validate different landscape connectivity approaches that locate ecological corridors.

Connectivity conservation planning aims to maintain or restore ecological corridors for multiple target species but this generalized goal comes up against several limits. The application of graph and circuit theory - or even individual-based models - requires species observation data and is computationally intensive. Furthermore, combining the results for a wide range of species creates theoretical problems such as how to generalize a patch-corridor-matrix model for species with different ecological requirements (Forman 1995). These limitations are overcome in different ways, sometimes through hypotheses that can distort the theory (e.g. Santini et al. 2016; Albert et al. 2017; Mimet et al. 2016; Sahraoui et al. 2017). A first option is to use land cover and expert opinion as a proxy for species presence and landscape resistance to movement to inform on potential multiple-species movements in the matrix (e.g. Tannier et al. 2012). A second option is to produce a habitat suitability map for each species by relating species-presence data with environmental predictors, then transform the habitat suitability map into matrix resistance, and finally to combine the maps for several species (e.g. Petsas et al. 2020). A third option relies on the concept of umbrella species, which "confer a protective umbrella to numerous co-occurring species" (Fleishman et al. 2000). Despite some progress, no single method has yet emerged as a reference (Diniz et al. 2018; Petsas et al. 2020; Meurant et al. 2018; Dickson et al. 2019). A validation procedure that is capable of determining the most relevant landscape connectivity approach could fill this knowledge gap.

The corridor locations predicted by different connectivity models can be validated with telemetry data or reference genetic distances (Koen et al. 2014; Coulon et al. 2015; Pinaud et al. 2017; Zeller et al. 2018; Finch et al. 2020). For example, Coulon et al. (2015) compared the correlation among between-population genetic distances and between-patch distances related to circuit theory, least-cost paths and individualbased modelling. Zeller et al. (2018) used validation methods based on observed dispersal paths defined from GPS locations to compare the output of connectivity approaches based on resistance surfaces estimated from presence-only data, telemetry and genetic data. However, in a review of the use of biological data in combination with landscape graphs, Foltête et al. (2020) found that telemetry and molecular data represent only $8.4 \%$ of the studies and are much less used than presence data, that can be easily extracted from existing databases, especially in studies with operational objectives. Therefore, further validation procedures are required. Foltête et al. (2020) found few papers that used biological data (regardless of data type) both a priori and a posteriori while the classical statistical procedure of validation consists in calibrating a model with a subsample of data and validating it with another 
subsample (Fielding and Bell, 1997). The a priori use of biological data informs landscape connectivity approaches of species requirements (e.g. Duflot et al. 2018). The a posteriori use of biological data is based on the statistical inference of biodiversity indices such as species abundance (Pinaud et al. 2017; Poli et al. 2019; but see Osipova et al. 2019). Inference makes it possible to compare network-based metrics according to coefficient of determination or likelihood-based indices. However, these indices are not directly related to ecological corridor locations. Finally, very few of the studies that have explicitly sought to map ecological corridors actually attempted to validate their approaches (Wade et al. 2019). Validation procedures that can be routinely applied with easily accessible independent data are thus critically needed. Taking advantage of the classical data partitioning procedure used in statistics to calibrate and validate landscape connectivity approaches with independent species presence data could fill this gap.

In this study, we propose a new validation procedure based on independent species-presence data to evaluate the accuracy of the locations of ecological corridors predicted by landscape connectivity models. We applied the procedure to forest birds in two forested mountain ranges in the French Alps, separated by an agricultural landscape. This landscape is a suitable situation for identifying dispersal corridors for forest species. Our validation method is based on the hypothesis that the concerned species are more likely to be found along or near their predicted corridors, provided these corridors were properly modelled. We applied this validation procedure to a set of four forest bird species. We compared three modelling approaches based on circuit theory to design multispecies corridors and selected the most valid among them. The three approaches were: (i) a habitat approach that relies upon a land cover map used as a proxy for species presence; (ii) an umbrella-species approach based on presence-only data of Sitta europea, an umbrella species for woodpeckers, and (iii) a multispecies approach based on presenceonly data of Sitta europea and three woodpecker species: Dendrocopos major, Dryocopos martius and Dendrocopos minor.

\section{Materials And Methods}

Study area and land cover map

The study area covers $755 \mathrm{~km}^{2}$ and is located in the northern French Alps (latitude: 45.223826 , longitude: 5.453339). Two mostly forested mountain massifs are located along the western and the eastern edges of the study area: the Chambarans Range to the west and the Vercors Range, which is also a Regional Natural Park, to the east (Fig. 1). These ranges were digitized from aerial photography (2015) of the study area. Both massifs are considered core areas of biodiversity $\left(124 \mathrm{~km}^{2}\right)$. They are separated from each other by a rural matrix $\left(631 \mathrm{~km}^{2}\right)$, which concentrates several potential dispersal barriers along the Isère River valley. Several kilometres along both sides of the river are occupied by urban areas linked with transport infrastructure, a concentration of intensive walnut orchards and agricultural fields. Land cover (Fig. 1; Supplementary Information, Appendix S1) is mainly composed of forests (patch area $>0.5 \mathrm{ha}$, $32 \%$ ) and agriculture (33\%), followed by orchards (14\%), urban areas $(11 \%)$, small woodlands (patch area $\leq 0.5 \mathrm{ha}$ ) and hedgerows (7\%) and water (streams and water bodies, $2 \%$ ). 
Species data and correction for sampling bias

We extracted presence data for the period 2014 to 2019 from the French Bird Protection League's database: 653 presence records for Sitta europea, and 1156, 46 and 41 for Dendrocopos major, Dryocopos martius and Dendrocopos minor, respectively. We used this presence data to define the boundaries of the study area from a convex hull (extended by a buffer of $100 \mathrm{~m}$ ) in order to exclude unprospected areas and avoid extrapolation. To correct for sampling bias, we followed Kramer-Schadt et al.'s (2013) spatial filtering method to remove nearby presence points according to a threshold distance (if too close, presence points could be redundant). This distance was defined as $100 \mathrm{~m}$ based on species home-range size (Supplementary Information, Appendix S2). Spatial filtering retained 396, 665, 43 and 31 points for Sitta europaea, Dryocopos major,Dryocopus martius and Dendrocopos minor, respectively. We hypothesized that the focal bird species could move from one core area to the other (i.e. from one massif to the other) without passing through intermediate habitat patches given: (1) maximal species dispersal distances ranged between 12.0 and $54.1 \mathrm{~km}$ (Supplementary Information, Appendix S2), (2) minimal distance between the two core areas was $11.1 \mathrm{~km}$ (Fig. 1), and (3) the potential dispersal barriers were spatially concentrated within a width of a few kilometres along the Isère Valley (Fig. 1).

Landscape connectivity approaches and assumptions

First, we created resistance surfaces defined according to (1) expert opinions coupled with scientific literature (approach 1, see below) and (2) Maxent models based on species presence-only data (Phillips et al. 2006; approaches 2 and 3). Then, the resistance surfaces were used with Circuit theory and the Linkage Mapper toolbox to define ecological corridors between the two core areas of biodiversity (McRae et al. 2008).

Approach 1, hereafter called "habitat", was based on the following assumptions: (1) land cover is a good proxy for species presence, and (2) land cover transformation, from expert opinion and the literature, is a good proxy for matrix resistance. Following previous parameterizations applied to forest mammals, resistance values were fixed to 1 for forest, 10 for small woodlands and hedgerows, 300 for orchards, 700 for agriculture, 900 for water and 1000 for urban areas (Verbeylen et al. 2003; Avon and Bergès 2016). These resistance values were also considered valid for forest birds.

Approach 2, hereafter called "umbrella species", consisted in modelling functional connectivity with Maxent from presence-only data of Sitta europaea to predict a habitat suitability index (HSI). S. europaea is a secondary cavity nester and an umbrella species for woodpeckers (Kotaka et al. 2002). This approach was based on the following assumptions: (1) umbrella-species habitat suitability is a good proxy for other species' presence, and (2) transformation of umbrella-species habitat suitability is a good proxy for matrix resistance. We calibrated the habitat suitability model using 198 presence data $(50 \%)$ through the Maxent software. The landscape metrics were derived from the land cover map and calculated with the Chloe-4.0 software (Boussard and Baudry 2017). We calculated the proportion of each land cover class using sliding windows (buffer radius of $100 \mathrm{~m}, 5 \mathrm{~m}$ between two adjacent windows). The windows were also used to calculate a landscape heterogeneity index: the Shannon 
diversity index or SHDI (Boussard and Baudry 2017). Buffer sizes were defined to prevent the windows around the points from overlapping. Checking for correlations among the landscape metrics indicated that they were not excessively correlated (Pearson's correlation coefficient $<0.70$ ). The importance of the individual landscape metrics and uncertainties were assessed with a Jackknife test based on three random selections of background points (or pseudo-absence; Phillips et al. 2009). Then, following Keeley et al. (2016) and Duflot et al. (2018), the habitat suitability index (HSI) was transformed into resistance values (ranging from 1 to 1000) following a negative exponential transformation function to strengthen the barrier effect of the least favourable areas.

If $\mathrm{HSI} \geq$ threshold (in species habitat): resistance was assigned to 1 .

If $\mathrm{HSI}<$ threshold (in matrix): we used Eq. 1 to assign resistance.

$$
\text { Resistance }=e^{\frac{\ln (0.001)}{\text { threshold }} \times H S I} \times 10^{3}(\text { eq.1) }
$$

Resistance is inversely proportional to the permeability of the matrix. The function (eq. 1) assigned a resistance value of 1000 when $\mathrm{HSI}$ equalled 0 and of 1 when $\mathrm{HS} /$ was greater than or equal to the HSI threshold defined by Liu et al. (2013).

Approach 3, hereafter called "multispecies", consisted first in modelling functional connectivity separately for the three woodpecker species Dendrocopos major, Dryocopus martius and Dendrocopos minor using $50 \%$ of the presence data (respectively 332, 21 and 15 presence points) following the method presented in approach 2, then combining the three single-species connectivity maps (see next paragraph) and the Sitta europaea map to obtain a multi-species connectivity map. Single-species connectivity maps were standardized to give the same weight to each of the four species. Approach 3 was based on the assumption that transformation of species habitat suitability is a good proxy for matrix resistance. The validity of maxent models used in approaches 2 and 3 were evaluated using the AUC index (Area Under the Curve; Fielding and Bell 1997).

For the three approaches, we used the ArcMap v.10.5.1 toolbox "Linkage Mapper Toolkit" based on circuit theory (McRae et al. 2008) to map the cumulative current showing all the dispersal paths between the two core areas and then to locate the most important paths, i.e. those that concentrate potential flows of individuals (McRae et al. 2008). We adjusted the parameters as follows: the intensity of the reservoirs was set at 1 Ampere, the current was calculated from the "pairwise" mode, and the two maps produced from the injection of current into the core areas were cumulated. This method is based on the assumption that species randomly move across the landscape and that any of the possible paths between the two biodiversity reservoirs could be taken (Dickson et al. 2019).

Validating the location of the ecological corridors 
To validate the location of the corridors, the cumulative current flow resulting from the three approaches were vectorised with three thresholds (at the $55^{\text {th }}, 65^{\text {th }}$ and $75^{\text {th }}$ quantiles) in order to calculate (i) the proportion of overlaid corridors among approaches, as a measure of consistency, and (ii) the resistance distance between independent presence points and the closest corridors, as a validation index. Only the polygons that continuously linked (i.e. with no breaches) the two core areas were considered corridors. Fifty percent of the data were dedicated to validation i.e. 198, 333, 22 and 16 presence points for Sitta europaea, Dendrocopos major, Dryocopus martius and Dendrocopos minor, respectively. Points located outside the convex rectangle defined by the corridors were removed since there was no corridor to validate. Finally, we used $162,294,14$ and 14 validation points with the $55^{\text {th }}$ quantile threshold; 149,263 , 11 and 13 validation points with the $65^{\text {th }}$ quantile threshold; and $118,211,11$ and 11 validation points with the $75^{\text {th }}$ quantile threshold for Sitta europaea, Dendrocopos major, Dryocopus martius and Dendrocopos minor, respectively. We derived the following validation index from the validation points:

\section{Corridor score $=\frac{1}{N} \sum_{i=1}^{N}\left(\frac{\text { dist.moy.random. } i \text {-dist.moy.observed. } i}{\text { dist.moy.random. } i}\right)$}

\section{Corridor score}

where $N$ is the number of random draws $i$, dist.moy.observed. $i$ is the average cost distance to the corridors from the validation points for draw $i$, and dist.moy.random. $i$ is the average cost distance to the corridors from randomly selected points in the landscape for draw $i$. The corridor score index was obtained by averaging 100 random draws $(N=100)$ from a number of random points equal to the number of validation points. An index close to 1 means the validation points are close to the corridor in terms of resistance distance, which validates the hypothesis that the corridor, or its nearby environment, concentrates the potential dispersal flows. An index close to 0 means the approach is no better than a null model and invalidates the above hypothesis. A negative index means that the matrix, not the corridor, concentrates the potential dispersal flows. As the difference between dist.moy.random. $i$ and dist.moy.observed. $i$ is sensitive to the distribution of resistance range values, we divided this difference by dist.moy.random. $i$ to calculate the corridor score. As a consequence, the corridor score is robust to the transformation function used to convert the HSI into resistance values (Supplementary Information, Fig. S1). The validation index was calculated for each species, approach and threshold of cumulative current. We tested the sensitivity of the validation index to these three parameters with ANOVA, for simple effects and all dual interactions. All statistical analyses were performed with R software v.3.6.0.

\section{Results}

Habitat suitability model

The AUC indices ranged between 0.70 and 0.72 , except for $D$. martius for which Maxent model validity was rather low $(A U C=0.63)$. Variable importance ranking showed that the two most important landscape metrics, for the four species, include proportion of forest or water, or the Shannon diversity index 
(Supplementary Information, Fig. S2). The Shannon diversity index always had either a null or positive effect on species presence, indicating that the species required multiple land covers such as forest and water. Proportion of forest and water were positively correlated with species presence, except when forest and water proportions were very high (with a few exceptions depending on species, Supplementary Information, Fig. S2). The effect of the proportion of small woodlands and hedgerows was not consistent among species, while the effect of the proportion of orchards and urban areas was generally negative. The response of Dendrocopos minor differed from the other three species: for this species, the effect of forest proportion did not show a clear trend and the proportion of small woodlands and hedgerows had a negative effect.

\section{Consistency among methods}

The multispecies and umbrella-species approaches showed globally similar locations for the highest current values but the habitat approach differed (Fig. 2). From the highest $\left(75^{\text {th }}\right)$ to the lowest $\left(55^{\text {th }}\right)$ quantile, the proportion of corridors shared between the multispecies and the umbrella-species approaches ranged from 0.74 to 0.83 , between the multispecies and the habitat approaches from 0.44 to 0.84 , and between the umbrella-species and the habitat approaches from 0.44 to 0.60 (Supplementary Information, Fig. S3). An example of the consequences of these differences on corridor design is provided in Supplementary Information (Supplementary Information, Appendix S3).

\section{Corridor validation}

Corridor score depended on approach $(F=387.5, P<0.0001)$, species $(F=887.3, P<0.0001)$, threshold quantile $(F=364.0, P<0.0001)$ and the interactions between species and approach $(F=76.1, P<0.0001)$ and between species and threshold quantile ( $F=93.3, P<0.0001$, Supplementary Information, Fig. S4). The multispecies approach obtained the highest corridor score $(0.69 \pm 0.12)$, followed by the umbrella-species approach $(0.55 \pm 0.25)$, then the habitat approach with the lowest score $(0.38 \pm 0.37)$ (Fig. 3). Regardless of the approach, the corridor score decreased from $S$. europaea $(0.70 \pm 0.11)$, to $D$. major $(0.55 \pm 0.13), D$. martius $(0.47 \pm 0.30)$ and $D$. minor $(0.39 \pm 0.42)$. For $S$. europaea, the corridor scores were similar for the umbrella-species approach and the multispecies approach. The median corridor score was the lowest for D. minor $(0.39 \pm 0.42)$, and especially low with the habitat approach $(-0.23 \pm 0.38)$. Additional results showed that the corridor score was robust to the distribution of the resistance value range (Supplementary Information, Fig. S1).

\section{Discussion}

We propose a new procedure to validate ecological corridor locations, based on independent presenceonly data, under the hypothesis that species should occur within or near the corridors. The corridor score can be computed from Euclidean or resistance distances and is robust to the distribution of the resistance value range. For example, the score can be used to select the best way to classify resistance values or to transform habitat suitability into resistance. Here, we illustrated the validation procedure by 
comparing different landscape connectivity approaches used to map multispecies corridors and selecting the most accurate approach. Our results have important theoretical and practical implications for managers and stakeholders concerned with connectivity conservation and restoration planning, who wish to validate connectivity approach assumptions and define corridor locations.

\section{Species responses to landscape metrics}

Our results showed that species presence could benefit from a diversity of land covers including forest, water and small woodlands and hedgerows. This complementation effect indicates that these land cover have a positive effect as long as they are not too dominant in the local environment (Dunning et al. 1992). This result relates to the importance of riparian forests, which allow species to move along streams. The role of riparian forests as ecological corridors as well as their use by woodpeckers have been highlighted (Gillies and St. Clair 2008; Weissteiner et al. 2016; Kosiński et al. 2018). Cultivated fields, orchards and urban areas had a consistently negative impact on species presence, except for Dendrocoptes minor. this bird mainly responded positively to the Shannon diversity index and to the proportion of water, and negatively to the proportion of small woodlands and hedgerows, in concordance with its ecology (Myczko et al. 2014; Rassati 2015). D. minor's differing response was expected given that the species is more generalist than the other three and is not rare in open habitats (Rassati 2015).

Consistency in ecological corridor location among methods

The ecological corridors were much more concordant between the multispecies and the umbrella species approaches than between these two approaches and the habitat approach. This may be explained by the similarity between the first two methods, which both integrate species data related to landscape metrics. Meurant et al. (2018) also compared different selections of surrogate species for spatial prioritization with reference to the full set of species. In contrast with our results, they concluded that umbrella species are poor indicators of many species' requirements and that an indirect approach based on habitat is preferable even if important areas, for landscape connectivity conservation, may not be identified. In our case, the concordance between the multispecies and the umbrella-species approaches was likely due to an appropriate choice of the umbrella species, since Sitta europea is a good surrogate for related woodpeckers (Kotaka et al. 2002). In contrast, the umbrella species selected by Meurant et al. (2018) is only a moderately effective surrogate, though for a wider range of species (14 species).

Validation of ecological corridor locations

The corridor score was higher for the multispecies and the umbrella-species approaches and lower for the habitat approach. The ability of the multispecies approach to accurately locate ecological corridors for several species is in accordance with previous findings (Carroll et al. 2001; Roberge and Angelstam 2004). We concluded that the assumption underlying the multispecies approach is the most realistic: species HSI are good proxies for matrix resistance when identifying multispecies ecological corridors. The gap between the multispecies approach and the habitat approach could be explained because multispecies presence data better reflect the reality than do habitat data. This difference is also partly due 
to how the landscape is modelled: either locally for the habitat approach, or accounting for the surrounding landscape context for the multispecies and the umbrella-species approaches. Indeed, the relative importance of local and landscape-scale factors can depend on landscape context and species (Howell et al. 2000; Walter et al. 2017) and the importance of landscape factors has been highlighted for woodpeckers (Gil-Tena et al. 2012; Lõhmus et al. 2016).

Some studies used inference to select the best connectivity metrics according to the quality of the fit defined from a coefficient of determination or likelihood-based indices (e.g. Poli et al. 2017). These indices are only indirectly related to the spatial configuration of the ecological network, which makes them less useful for practitioners concerned with ecological network design. Osipova et al. (2019) used a combination of models to assess the links between connectivity metrics and abundance, density and total number of elephants with aerial and field surveys. Their significant investigatory effort provides a body of evidence supporting the fact that corridor delineation derived from a landscape-connectivity approach has a strong predictive power and is useful in spatial conservation prioritization (Osipova et al. 2019).

Other studies used the standardized difference and the z-scores of accumulated costs, at observed and random radio-tracking fixes, to validate ecological corridor location, though the cost of telemetry technology greatly limits its general application (Driezen et al. 2007; Pinaud et al. 2017; Finch et al. 2020). Independent data collected during specific sampling campaigns (capture-release-recapture, camera sampling, sand traps or vehicle collision data) can be used efficiently to validate landscape connectivity approaches, but only for the species that can be detected in such a way (Koen et al. 2014; Balbi et al. 2020; Laliberté and St-Laurent 2020; but see Cerqueira et al. 2021). When the cost of collecting data for validation is acceptable, these methods are relevant and can complement our internal validation procedure.

Influence of species on the degree of validation

We also tested corridor score sensitivity and performance against species and the current threshold we used to delineate corridors. The corridor score was the highest for Sitta europaea, certainly because the presence data of this species were used for calibration in two of the three models (umbrella and multispecies models). The median corridor score was the lowest for Dendrocoptes minor. The median corridor score for the habitat approach was negative for this species, indicating that the ecological corridor locations were less accurate than in a null model, and that our hypotheses on matrix resistance were globally inconsistent. This result is easily explained because the proportion of water in the local environment (and the Shannon diversity index) was the main driver of environmental suitability and not the proportion of forest. This illustrates the ability of our validation procedure to detect a misclassification of matrix resistance values, even with only a few validation points. Interestingly, the multispecies approach performed similarly to the umbrella species approach for Sitta europaea, indicating that including data from other species did not decrease the accuracy of the multispecies approach for this species. Both methods worked equally well for Sitta europaea and Dendrocopos major. 
The multispecies model, followed by the umbrella-species model, performed better than the habitat model for $D$. martius and $D$. medius. For $D$. martius, the habitat approach had a high corridor score only when the discrimination of ecological corridors from the matrix was not very selective (i.e. when the $55^{\text {th }}$ quantile of current values was used to delineate the corridors). Overall, the accuracy of the different models varied according to the species used for validation. This result might be partly due to differences in the number of presence points and in the validity of the Maxent models. Interestingly, the AUC index only showed a lower validity of the habitat suitability model for $D$. martius, while the corridor score showed more contrasted results among species. Beyond the validity of habitat suitability models, we highlight the need to validate also the landscape connectivity models according to their final outputs (ecological corridor locations). Finally, implementing a multispecies approach should guarantee maximal prediction accuracy in most cases.

Limits, advantages and perspectives

Our study did not overcome the limitations recently debated concerning the link between presence data, dispersal movement and the effective reproduction of migrants (Robertson et al. 2018; Fletcher et al. 2019). Presence data relate both to habitat suitability and species movements, and both processes are merged when movements decrease due to mortality risk or avoidance of less suitable types of land cover. Fletcher et al. (2019) question the consequences of neglecting to distinguish between these two processes, though they do recognize that the focus on matrix resistance had led to major advances in the understanding of connectivity. They propose a new connectivity model that separates mortality and movement behaviour. We acknowledge that presence data are indirectly related to movement and do not make it possible to discriminate between foraging, dispersal and migration, or to quantify the successful reproduction of migrants, with its consequences on genetic population diversity (Jeltsh et al. 2013).

However, these limits are not specific to our study and our validation procedure still has several theoretical and practical advantages: (i) it provides a validation procedure based on easily accessible data; (ii) it can be used to select the most realistic landscape connectivity approach; (iii) it can detect a misclassification of matrix resistance values from only a few validation points and can help select the best function to transform habitat suitability into resistance values; (iv) it is independent from the modelling framework (e.g. expert opinions, least-cost paths or circuit theory) because it evaluates one final output of a given landscape connectivity approach (i.e. ecological corridor locations) and not only an intermediate output (such as resistance values) that imply to use a specific framework (circuit theory); and $(v)$ it is easy to calculate after using softwares designed for connectivity conservation planning (McRae et al. 2008; Foltête et al. 2012; Saura and Torné 2009).

To reinforce our validation procedure for landscape connectivity approaches, we need to evaluate how the corridor score ranks different corridor design methods with more robust validation indices based on telemetry or genetic distances (Coulon et al. 2015). These objectives are within the reach of both empirical and theoretical studies that use in silico controlled experiments. Finally, further work is required 
to assess the potential of our validation procedure in order to dispense with the costly use of telemetry and genetic data.

\section{Declarations}

\section{Funding}

This work was supported by the FEDER project "Trame verte forestière" (contract n RA0017232).

\section{Conflicts of interest}

The authors declare no conflict of interest.

\section{Ethics approval}

All authors agreed with ethics approval.

\section{Consent to participate}

All authors agreed with the content and that all gave explicit consent to submit and that they obtained consent from the responsible authorities at the institute where the work has been carried out.

\section{Consent for publication}

All authors agreed with the content and the submission of the manuscript.

\section{Availability of data and material}

Not applicable. The owner of the data is the French Bird Protection League (Ligue de Protection des Oiseaux, LPO).

\section{Code availability}

Not applicable.

\section{Authors' contributions}

Listed at the separate title page.

\section{References}

1. Albert CH, Rayfield B, Dumitru M, Gonzalez A (2017) Applying network theory to prioritize multispecies habitat networks that are robust to climate and land-use change. Conserv Biol 31(6):1383- 
2. Avon C, Bergès $L$ (2016) Prioritization of habitat patches for landscape connectivity conservation differs between least-cost and resistance distances. Landscape Ecol 31(7):1551-

3. Balbi M, Croci S, Petit EJ, Butet A, Georges R, Madec L, et al (2020) Least-cost path analysis for urban greenways planning: A test with moths and birds across two habitats and two cities. $J$ Appl Ecol.

4. Boussard H, Baudry J (2014). Chloe: A software for Landscape Pattern Analysis.

5. Carroll C, Noss RF, Paquet PC (2001) Carnivores as focal species for conservation planning in the Rocky Mountain region. Ecol Appl 11(4):961-

6. Cerqueira RC, Leonard PB, da Silva LG, Bager A, Clevenger AP, Jaeger JAG, Grilo C (2021) Potential movement corridors and high road-kill likelihood do not spatially coincide for felids in Brazil: implications for road mitigation. Environ Manage 67:412-

7. Coulon A, Aben J, Palmer SCF, Stevens VM, Callens T, Strubbe D, et al (2015) A stochastic movement simulator improves estimates of landscape connectivity. Ecology 96(8):2203-

8. Dickson BG, Albano CM, Anantharaman R, Beier P, Fargione J, Graves TA, et al (2019) Circuit-theory applications to connectivity science and conservation. Conserv Biol 33(2):239-

9. Diniz MF, Machado RB, Bispo AA, Júnior PDM (2018) Can we face different types of storms under the same umbrella? Efficiency and consistency of connectivity umbrellas across different patchy landscape patterns. Landscape Ecol 33(11):1911-

10. Driezen K, Adriaensen F, Rondinini C, Doncaster CP, Matthysen E (2007) Evaluating least-cost model predictions with empirical dispersal data: a case-study using radiotracking data of hedgehogs (Erinaceus europaeus). Ecol Model 209(2-4):314-

11. Duflot $R$, Avon $C$, Roche $P$, Bergès $L$ (2018) Combining habitat suitability models and spatial graphs for more effective landscape conservation planning: An applied methodological framework and a species case study. J Nat Conserv 46:38-

12. Dunning JB, Danielson BJ, Pulliam HR (1992) Ecological processes that affect populations in complex landscapes. Oikos 169:175.

13. Fielding AH, Bell JF (1997) A review of methods for the assessment of prediction errors in conservation presence/absence models. Environ Conserv 38-

14. Finch D, Corbacho DP, Schofield H, Davison S, Wright PG, Broughton RK, Mathews F (2020) Modelling the functional connectivity of landscapes for greater horseshoe bats Rhinolophus ferrumequinum at a local scale. Landscape Ecol 35(3):577-

15. Fleishman E, Murphy DD, Brussard PF (2000) A new method for selection of umbrella species for conservation planning. Ecol Appl 10(2):569-

16. Fletcher RJ, Sefair JA, Wang C, Poli CL, Smith TA, Bruna EM, et al (2019) Towards a unified framework for connectivity that disentangles movement and mortality in space and time. Ecol Lett 22(10):1680- 
17. Foltête JC, Clauzel C, Vuidel G (2012) A software tool dedicated to the modelling of landscape networks. Environ Modell Softw 38:316-

18. Foltête JC, Savary P, Clauzel C, Bourgeois M, Girardet X, Sahraoui Y, et al (2020) Coupling landscape graph modeling and biological data: a review. Landscape Ecol 35(5):1035-

19. Forman RT (1995) Some general principles of landscape and regional ecology. Some general principles of landscape and regional. Landscape Ecol 10(3):133-

20. Gilbert-Norton L, Wilson R, Stevens JR, Beard KH (2010) A meta-analytic review of corridor effectiveness. Conserv Biol 24(3):660-

21. Gillies CS, St. Clair CC (2010) Functional responses in habitat selection by tropical birds moving through fragmented forest. J Appl Ecol 47(1):182-

22. Gil-Tena A, Brotons L, Fortin MJ, Burel F, Saura S (2013) Assessing the role of landscape connectivity in recent woodpecker range expansion in Mediterranean Europe: forest management implications. Eur J For Res 132(1):181-

23. Hanski I (1998) Metapopulation dynamics. Nature 396(6706):41-

24. Howell CA, Latta SC, Donovan TM, Porneluzi PA, Parks GR, Faaborg J (2000) Landscape effects mediate breeding bird abundance in midwestern forests. Landscape Ecol 15(6):547-

25. Jeltsch F, Bonte D, Pe'er G, Reineking B, Leimgruber $P$, Balkenhol N, et al (2013) Integrating movement ecology with biodiversity research-exploring new avenues to address spatiotemporal biodiversity dynamics. Movement Ecol 1(1):1-

26. Jongman RH, Bouwma IM, Griffioen A, Jones-Walters L, Van Doorn AM (2011) The pan European ecological network: PEEN. Landscape Ecol 26(3):311-

27. Keeley AT, Beier P, Gagnon JW (2016). Estimating landscape resistance from habitat suitability: effects of data source and nonlinearities. Landscape Ecol 31(9):2151-

28. Koen EL, Bowman J, Sadowski C, Walpole AA (2014) Landscape connectivity for wildlife: development and validation of multispecies linkage maps. Methods Ecol Evol 5(7): 626-

29. Kosiński Z, Pluta M, Ulanowska A, Walczak $Ł$, Winiecki A, Zarębski M (2018) Do increases in the availability of standing dead trees affect the abundance, nest-site use, and niche partitioning of great spotted and middle spotted woodpeckers in riverine forests?. Biodivers Conserv 27(1):123-

30. Kotaka N, Matsuoka S (2002) Secondary users of Great Spotted Woodpecker (Dendrocopos major) nest cavities in urban and suburban forests in Sapporo City, northern Japan. Ornithol Sci 1(2):117-

31. Kramer-Schadt S, Niedballa J, Pilgrim JD, Schröder B, Lindenborn J, Reinfelder V, et al (2013) The importance of correcting for sampling bias in MaxEnt species distribution models. Divers Distrib 19(11):1366-

32. Laliberté J, St-Laurent MH (2020) Validation of functional connectivity modeling: The Achilles' heel of landscape connectivity mapping. Landscape Urban Plan 202:103878.

33. Liu C, White M, Newell G (2013) Selecting thresholds for the prediction of species occurrence with presence-only data. J biogeogr 40(4):778- 
34. Lõhmus A, Nellis R, Pullerits M, Leivits M (2016) The potential for long-term sustainability in seminatural forestry: a broad perspective based on woodpecker populations. Environ Manage 57(3):558-

35. McRae BH, Dickson BG, Keitt TH, Shah VB (2008) Using circuit theory to model connectivity in ecology, evolution, and conservation. Ecology 89(10):2712-

36. Meurant M, Gonzalez A, Doxa A, Albert CH (2018) Selecting surrogate species for connectivity conservation. Biol Conserv 227:326-

37. Mimet A, Clauzel C, Foltête JC (2016) Locating wildlife crossings for multispecies connectivity across linear infrastructures. Landscape Ecol 31(9):1955-

38. Myczko Ł, Rosin ZM, Skórka P, Tryjanowski P (2014) Urbanization level and woodland size are major drivers of woodpecker species richness and abundance. PLoS One 9(4):e94218.

39. Osipova L, Okello MM, Njumbi SJ, Ngene S, Western D, Hayward MW, Balkenhol N (2019) Validating movement corridors for African elephants predicted from resistance-based landscape connectivity models. Landscape Ecol 34(4):865-

40. Petsas P, Tsavdaridou Al, Mazaris AD (2020) A multispecies approach for assessing landscape connectivity in data-poor regions. Landscape Ecol 35(3):561-

41. Phillips SJ, Anderson RP, Schapire RE (2006) Maximum entropy modeling of species geographic distributions. Ecol Model 190(3-4):231-

42. Pinaud D, Claireau F, Leuchtmann M, Kerbiriou C (2018) Modelling landscape connectivity for greater horseshoe bat using an empirical quantification of resistance. J Appl Ecol 55(6):2600-

43. Poli C, Hightower J, Fletcher RJ (2020) Validating network connectivity with observed movement in experimental landscapes undergoing habitat destruction. J Appl Ecol 57(7):1426-

44. Rassati G (2015) Responsiveness to acoustic stimulation, distribution and habitat preferences of the Lesser Spotted Woodpecker, Dendrocopos minor, in Friuli-Venezia Giulia (North-eastern Italy). Riv Ital Ornitol 51-

45. Resasco J (2019) Meta-analysis on a decade of testing corridor efficacy: What new have we learned? Curr Landscape Ecol Rep 4(3):61-

46. Roberge JM, Angelstam PER (2004) Usefulness of the umbrella species concept as a conservation tool. Conserv Biol, 18(1), 76-85.

47. Robertson EP, Fletcher RJ, Cattau CE, Udell BJ, Reichert BE, Austin JD, Valle D (2018) Isolating the roles of movement and reproduction on effective connectivity alters conservation priorities for an endangered bird. P Natl Acad Sci USA 115(34):8591-

48. Sahraoui Y, Foltête JC, Clauzel C (2017) A multi-species approach for assessing the impact of landcover changes on landscape connectivity. Landscape Ecol 32(9):1819-

49. Santini L, Saura S, Rondinini C (2016) A composite network approach for assessing multi-species connectivity: an application to road defragmentation prioritisation. Plos one 11(10):e0164794. 
50. Saura S, Torne J (2009) Conefor Sensinode 2.2: a software package for quantifying the importance of habitat patches for landscape connectivity. Environ Modell Softw 24(1):135-

51. Tannier C, Foltête JC, Girardet X (2012) Assessing the capacity of different urban forms to preserve the connectivity of ecological habitats. Landscape Urban Plan 105(1-2):128-

52. Taylor PD, Fahrig L, Henein K, Merriam G (1993) Connectivity is a vital element of landscape structure. Oikos 571-

53. Tucker MA, Böhning-Gaese K, Fagan WF, Fryxell JM, Van Moorter B, Alberts SC, et al (2018) Moving in the Anthropocene: Global reductions in terrestrial mammalian movements. Science 359(6374):466 -

54. Vellend M (2010) Conceptual synthesis in community ecology. Q Rev Biol 85(2):183-

55. Verbeylen G, De Bruyn L, Adriaensen F, Matthysen E (2003) Does matrix resistance influence Red squirrel (Sciurus vulgaris L. 1758) distribution in an urban landscape? Landscape Ecol 18(8): 791-

56. Wade AA, McKelvey KS, Schwartz MK (2015) Resistance-surface-based wildlife conservation connectivity modeling: Summary of efforts in the United States and guide for practitioners. Gen. Tech. Rep. RMRS-GTR-333. Fort Collins, CO: U.S. Department of Agriculture, Forest Service, Rocky Mountain Research Station. 93 p.

57. Walter ST, Browne L, Freile J, Olivo J, González M, Karubian J (2017) Landscape-level tree cover predicts species richness of large-bodied frugivorous birds in forest fragments. Biotropica 49(6):838-

58. Weissteiner CJ, Ickerott M, Ott H, Probeck M, Ramminger G, Clerici N, et al (2016) Europe's green arteries-a continental dataset of riparian zones. Remote Sens 8(11):925.

59. Zeller KA, Jennings MK, Vickers TW, Ernest HB, Cushman SA, Boyce WM (2018) Are all data types and connectivity models created equal? Validating common connectivity approaches with dispersal data. Divers Distrib 24(7):868-

\section{Figures}




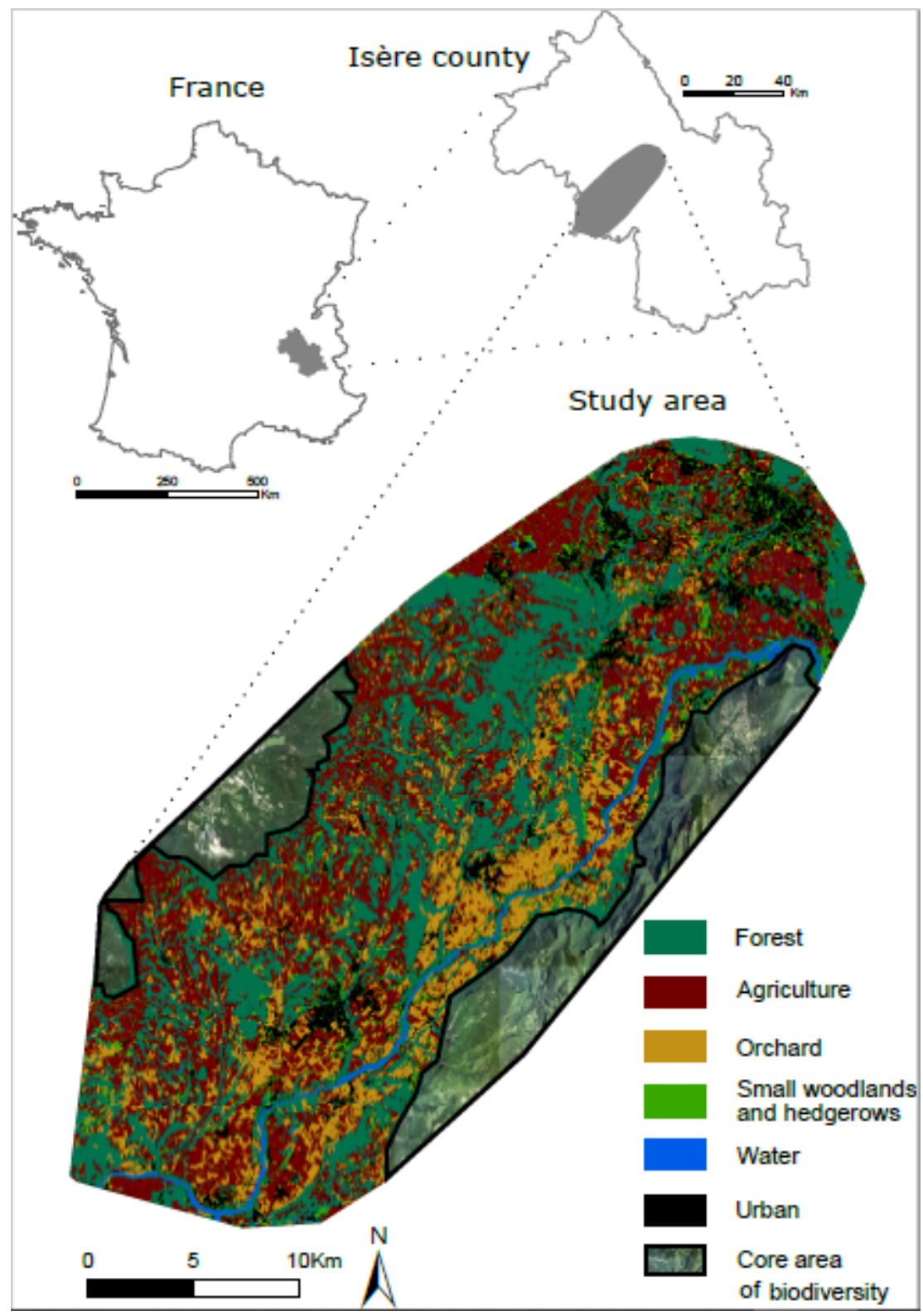

Figure 1

Study area with the land cover in the matrix and the core areas of biodiversity (determined by orthoimagery). Note: The designations employed and the presentation of the material on this map do not imply the expression of any opinion whatsoever on the part of Research Square concerning the legal status of any country, territory, city or area or of its authorities, or concerning the delimitation of its frontiers or boundaries. This map has been provided by the authors. 


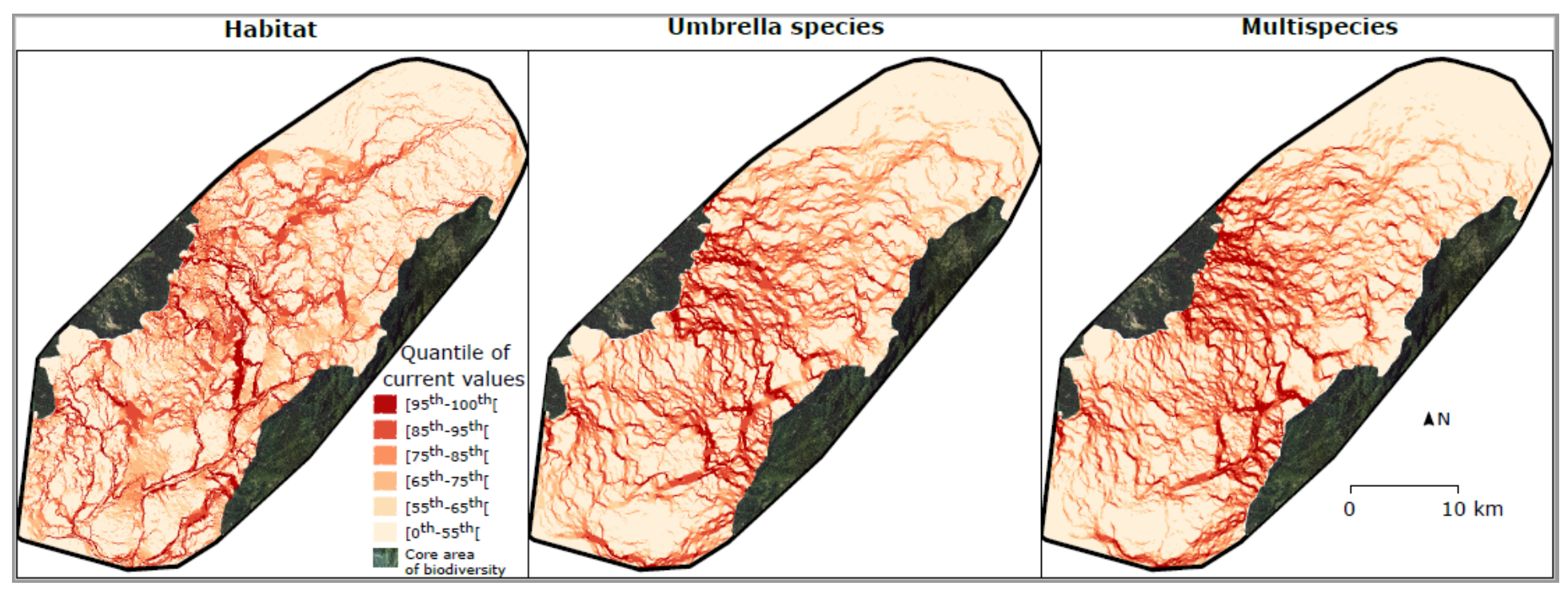

Figure 2

Comparison of the current maps for the three approaches used to define ecological corridors.

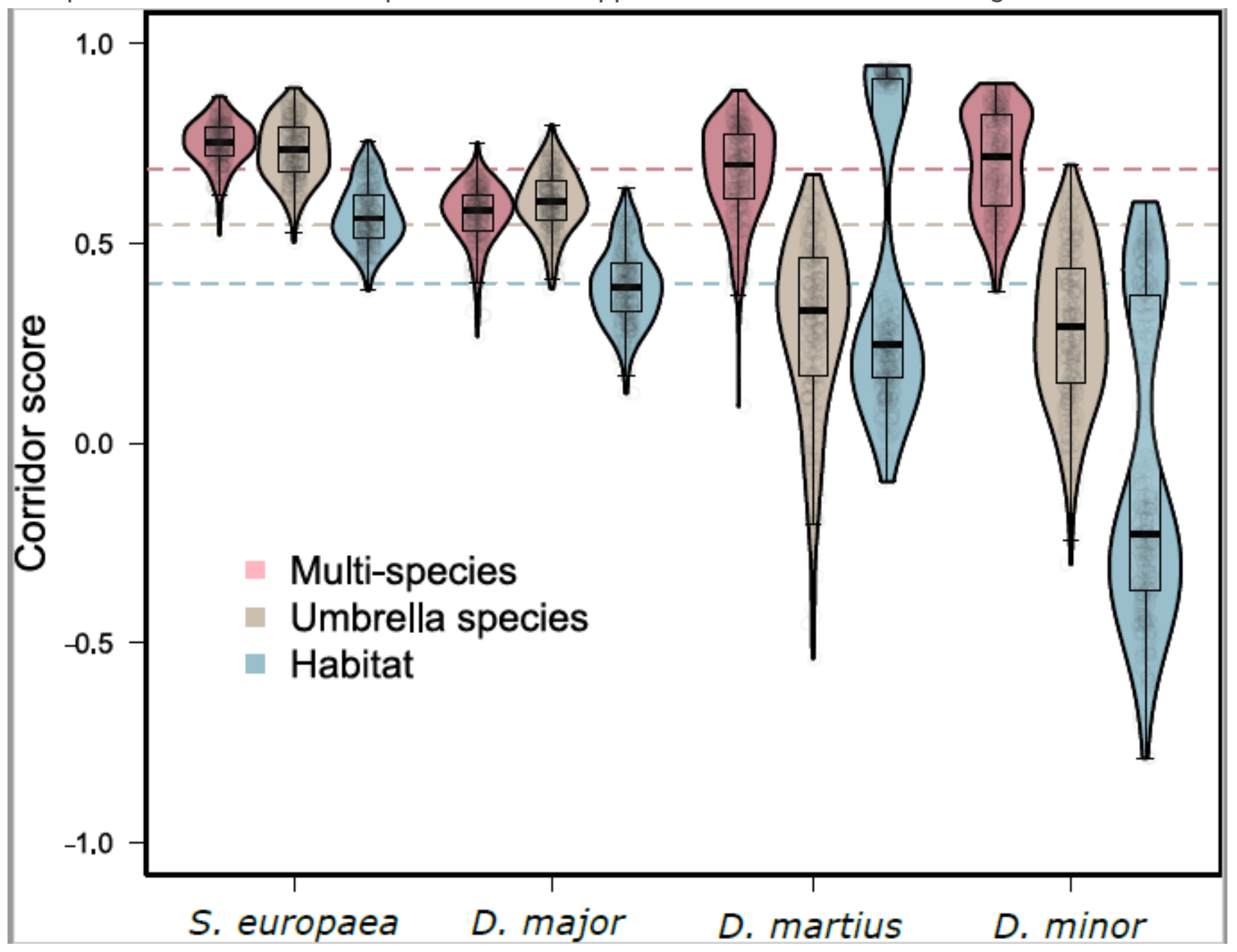

Figure 3 
Variations in corridor score according to landscape-connectivity approach and species used for validation. Corridor scores evaluate the accuracy of predicted ecological-corridor locations thanks to independent species validation points (see Methods section). The graph shows a combination of boxplots and violin plots representing quantile and kernel density for 100 comparisons of random draws (light grey points) with species validation points for the three thresholds of current values used to delineate the corridors. Dotted lines indicate median values according to the method. 